\title{
Effect of Carbonate Content on the Petrophysical Propersity of the Wufeng-Longmaxi Shales in the Sichuan Basin, China
}

YiJUN ZHENG ${ }^{1}$, YUHONG LIAO ${ }^{1, *}$, YUNPENG WANG ${ }^{1}$, YONGQIANG XIONG ${ }^{1}$, PING'AN PENG ${ }^{1}$

${ }^{1}$ Guangzhou Institute of Geochemistry, Chinese Academy of Sciences, PR China. (liaoyh@gig.ac.cn)

\section{Background Information and Method}

Changning and Fuling are the two depositional centers of the Wufeng and Longmaxi formations in the Sichuan Basin, China. There are significant differences in the gas content of the Wufeng-Longmaxi shales between these two areas[1]. In this study, two shallow wells named Shuanghe-1 and Sanquan-1 were drilled. The petrophysical properties, pore structure of organic matter (OM) and mineralogy of the Wufeng-Longmaxi shales from both wells, together with the Jiaoye 4 well from the Fuling shale gas field were comprehensively investigated and compared.

\section{Results}

The results indicate that organic-rich shale (total organic carbon $[\mathrm{TOC}]>2.0$ wt.\%) intervals in both Sanquan and Jiaoshiba town have high pore volume and low carbonate content, whereas the organic-rich shale intervals in Shuanghe town have much lower pore volume and porosity but higher carbonate content ( $\geqslant 10 \%$, mostly calcite) though the TOC contents of both shallow wells are quite similar. Furthermore, in Shuanghe-1, both total pore volume $\left(\mathrm{V}_{\text {total }}\right)$ and total specific surface area $\left(\mathrm{S}_{\text {total }}\right)$ of the organic-rich shale samples with similar TOC content decrease by approximately $30 \%$ when the carbonate content of the shale in Shuanghe-1 increases by $10 \%$, especially when the carbonate content is in the range of $10 \%-20 \%$. We believed that organic acids generated by organic-rich shales can lead to an extensive carbonate dissolution and subsequent calcite cementation in interparticle pores, microcracks and fractures within the organic-rich shale intervals. As a result, secondary organic pores don't have enough space to fully develop, resulting in lower shale pore volume and connectivity. Therefore, high carbonate content may be one critical geological factor that is responsible for the lower gas content in the WufengLongmaxi shale reservoirs in the southern Sichuan Basin.

[1] Zou et al. (2016) Petroleum Exploration and Development, 43, 166-178. 